\title{
Increased receptor activator of nuclear factor $\kappa \beta$ ligand/osteoprotegerin ratio exacerbates cartilage destruction in osteoarthritis in vitro
}

\author{
JI-ZHOU ZENG ${ }^{1,2}$, ZHEN-ZHONG WANG ${ }^{1}$, LI-FENG MA ${ }^{1}$, HAI MENG ${ }^{1}$, HAO-MIAO YU ${ }^{1}$, \\ WEN-HAO $\mathrm{CHENG}^{2}$, YA-KUI ZHANG ${ }^{2}$ and $\mathrm{AI} \mathrm{GUO}^{1}$ \\ ${ }^{1}$ Department of Orthopedics, Beijing Friendship Hospital, Capital Medical University, Beijing 100050; \\ ${ }^{2}$ Department of Orthopedics, Beijing Luhe Hospital, Capital Medical University, Beijing 101149, P.R. China
}

Received June 4, 2015; Accepted July 28, 2016

DOI: $10.3892 / \mathrm{etm} .2016 .3638$

\begin{abstract}
Osteoarthritis (OA) is a degenerative joint disease characterized by progressive cartilage destruction, matrix degradation and bony changes. Subchondral bone alterations in osteoarthritis are associated with cartilage destruction. It has previously been demonstrated that osteoprotegerin (OPG) and receptor activator of nuclear factor $\kappa \beta$ ligand (RANKL) mediate this process. The RANKL/OPG ratio is altered in OA chondrocytes compared with normal chondrocytes. In the pathogenesis of OA, abnormal expression levels of matrix metalloproteinase-13 (MMP-13) are secreted by chondrocytes has a vital role in the progression of cartilage erosion. In the present study, the effect of various RANKL/OPG ratios on MMP-13 expression levels was investigated in interleukin-1 $\beta$-stimulated SW1353 human chondrosarcoma cells. Cell viability was assessed by MTT assay and MMP-13 mRNA and protein expression levels were analyzed by quantitative reverse-transcription-quantitative polymerase chain reaction, ELISA and western blot analyses, respectively. The results demonstrated that an increase in MMP-13 mRNA and protein expression levels was observed with increasing RANKL/OPG ratio. These findings suggest that this mechanism may be used as a novel therapeutic strategy against OA.
\end{abstract}

\section{Introduction}

Osteoarthritis (OA) is the most common type of arthritis in adults worldwide, severely impairing patients' quality of life (1). OA is characterized by progressive degeneration of articular cartilage and bony changes, including increased

Correspondence to: Dr Ai Guo, Department of Orthopedics, Beijing Friendship Hospital, Capital Medical University, 95 Yong An Road, Beijing 100050, P.R. China

E-mail: guoaigj@163.com

Key words: receptor activator of nuclear factor $\kappa \beta$ ligand, osteoprotegerin, matrix metalloproteinase-13, osteoarthritis turnover of the subchondral bone, thinning of the trabecular structure, osteophytes, bone marrow lesions and sclerosis of the subchondral plate (2). Previous experimental and clinical studies have suggested that the structural integrity of articular cartilage is dependent on normal subchondral bone turnover, intact chondrocyte function and appropriate biomechanical stress $(3,4)$. Bone and cartilage health appear to be closely associated, and various studies have reported secondary positive effects on cartilage health when bone resorption is suppressed, or deterioration of cartilage when resorption is enhanced $(5,6)$.

As members of the tumor necrosis factor superfamily, the molecular triad of osteoprotegerin (OPG)/receptor activator of nuclear factor $\kappa \beta(\mathrm{RANK}) /$ receptor activator of nuclear factor $\kappa \beta$ ligand (RANKL) represents a key cytokine system for regulating bone metabolism $(7,8)$. In OA, remodeling of the subchondral bone is reported to be RANKL-dependent, and osteoblasts express RANKL in subchondral bone $(4,9)$. Furthermore, previous studies suggests that OPG is associated with the regulation of cartilage metabolism, as OPG-deficient mice exhibit thinned articular cartilage layers, severe destruction of growth plate cartilage and enhanced cartilage degradation with aging $(10,11)$. Structural integrity of articular cartilage is influenced by changes in subchondral bone as denser bone is detected below OA cartilage (2). RANKL and OPG are synthesized and expressed by articular chondrocytes in a position adjacent to subchondral bone $(12,13)$; therefore, these cytokines may affect bone turnover and alter bone density.

Despite the lack of detailed insight into the etiology and pathology of OA, it is well-documented that the degradation and destruction of type II collagen caused by matrix metalloproteinase-13 (MMP-13) has a key role in the occurrence and development of OA (14-16). Therefore, MMP-13 represents a target for the prevention of the onset or retardation of $\mathrm{OA}$ progression.

It has been demonstrated that the RANKL-OPG system is associated with the pathogenesis of OA $(10,17)$. MMP-13 is a crucial collagenase that mediates type II collagen degradation, which is an important component of cartilage (18-20). Based on these findings of previous studies $(21,22)$, in the present study SW1353 human chondrosarcoma cells stimulated by interleukin (IL) $-1 \beta$ were used as a cell model of OA to investigate the effects 
of RAKNL/OPG at various ratios on the MMP-13 mRNA and protein expression levels of SW1353 chondrosarcoma cells.

\section{Materials and methods}

Reagents and cell lines. Recombinant human OPG and RANKL were purchased from Sigma-Aldrich (Merck Millipore, Darmstadt, Germany), dissolved in double-distilled water, diluted to $100 \mu \mathrm{g} / \mathrm{ml}$ using Dulbecco's modified Eagle's medium (DMEM; Gibco; Thermo Fisher Scientific, Inc., Waltham, MA, USA), and subsequently stored at $-20^{\circ} \mathrm{C}$. IL- $1 \beta$ was stored at $-20^{\circ} \mathrm{C}$ at a concentration of $100 \mathrm{ng} / \mathrm{ml}$. The required concentrations of OPG, RANKL, and IL-1 $\beta$ used in the following experiments were prepared by further dilution with DMEM.

SW1353 human chondrosarcoma cells (Cell Applications Inc., San Diego, CA, USA) were cultivated in DMEM supplemented with $10 \%$ (v/v) fetal bovine serum and $100 \mathrm{U} / \mathrm{ml}$ penicillin-streptomycin solution at $37^{\circ} \mathrm{C}$ in a humidified atmosphere containing $5 \% \mathrm{CO}_{2}$. Prior to the addition of experimental components, SW1353 cells were seeded in a 6-well culture flask at a density of $\sim 10^{5}$ cells $/ \mathrm{cm}^{2} /$ well in serum-free DMEM supplemented with $100 \mathrm{U} / \mathrm{ml}$ penicillin-streptomycin to starve the cells for $24 \mathrm{~h}$.

MTT assay. Cytotoxicity of various ratios of OPG and RANKL/OPG (1:160, 1:80, 1:40, 1:20, 1:10, 1:5 and 1:2.5) to SW1353 cells was evaluated using the MTT assay. Final concentrations of OPG and RANKL were $200 \mathrm{ng} / \mathrm{ml}$ and $1.25,2.5,5,10,20,40$ and $80 \mathrm{ng} / \mathrm{ml}$. SW1353 cells were cultured in 96-well plates (5,000 cells/well) with OPG and RANKL/OPG and incubated for $24 \mathrm{~h}$. Subsequently, MTT regent (Sigma-Aldrich; Merck Millipore) was added to each well and the cells were incubated for a further $4 \mathrm{~h}$. Supernatants were removed, and DMSO (Sigma-Aldrich; Merck Millipore) was added to the wells to dissolve the formazan crystals. Optical absorbance values of each well were recorded at $450 \mathrm{~nm}$ using an enzyme-labeled meter (Thermo Fisher Scientific, Inc.). The same procedure was repeated three times.

ELISA. SW1353 cells were pre-treated with OPG and RANKL/OPG for $1 \mathrm{~h}$, which was followed by stimulation with IL-1 $\beta(5 \mathrm{ng} / \mathrm{ml})$ for $24 \mathrm{~h}$ or no treatment at all. The effect of IL-1 $\beta$, OPG and/or RANKL/OPG on the protein levels of MMP-13 secreted by SW1353 cells in the culture supernatant was evaluated by ELISA kits (ab100605; Abcam, Cambridge, UK), according to the manufacturer's instructions. All ELISA experiments were performed in triplicate.

Reverse transcription-quantitative polymerase chain reaction (RT-qPCR). Total cellular RNA was extracted using TRIzol reagent from SW1353 cells (Dingguochangsheng Biotechnology, Co., Beijing, China) according to the manufacturer's instructions. Extracted RNA was subsequently dissolved in diethylpyrocarbonate-treated water and stored at $-80^{\circ} \mathrm{C}$ prior to use. First-strand cDNA was synthesized using $1 \mu \mathrm{g}$ total RNA treated with DNase to remove genomic DNA with a PrimeScript-RT reagent kit (Tiangen Biotech, Beijing, China). PCR amplification was performed using specifically designed primers (Table I), the SYBR Premix Ex Taq (Takara Biotechnology Co., Ltd., Dalian, China) and the StepOne
Table I. Primers used for polymerase chain reaction analysis.

\begin{tabular}{lc}
\hline Target & Primer sequence \\
\hline MMP-13 & \\
Forward & 5'-CAGAACATCATCCCTGCCTCT-3' \\
Reverse & 5'-GCCCATCAAATGGGTAGAAG-3' \\
GAPDH & \\
Forward & 5'-CAGAACATCATCCCTGCCTCT-3' \\
Reverse & 5'-GCTTGACAAAGTGGTCGTTGAG-3'
\end{tabular}

MMP-13, matrix metalloproteinase-13.

Real-Time PCR System (Applied Biosystems; Thermo Fisher Scientific, Inc.). The PCR reaction contained the following: $4 \mu \mathrm{l}$ total RNA, $4 \mu \mathrm{l}$ 5X buffer, $1 \mu \mathrm{l}$ dNTPs (10 mM), $1 \mu \mathrm{l}$ oligo(dT)18 $(50 \mu \mathrm{M}), 0.5 \mu \mathrm{l}$ random primer $(100 \mu \mathrm{M}), 1 \mu \mathrm{l}$ MMLV-RT (200 U/ $\mu \mathrm{l})$ and $8.5 \mu \mathrm{l}$ DEPC $\mathrm{H}_{2} \mathrm{O}$ in a total volume of $20 \mu \mathrm{l}$. qPCR reaction volumes are presented in Table II. Typical thermal conditions were used as follows: Denaturalization at $95^{\circ} \mathrm{C}$ for $30 \mathrm{sec}$; annealing for 40 cycles at $60^{\circ} \mathrm{C}$ for $32 \mathrm{sec}$; and extension at $95^{\circ} \mathrm{C}$ for $15 \mathrm{sec}$. GADPH mRNA expression was used as an endogenous control. MMP-13 mRNA levels were normalized to those of GAPDH. All experiments were repeated three times and analyzed using the $2^{-\Delta \Delta \mathrm{Cq}}$ method (23).

Western blotting. Total protein was extracted using radio-immunoprecipitation assay buffer supplemented with $1 \%$ protease inhibitor cocktail (Roche Diagnostics, Indianapolis, IN, USA). Phosphorylated protein was obtained using a phosphorylated protein extraction kit (Roche Diagnostics). Protein samples $(40 \mu \mathrm{g})$ were separated by $12 \%$ sodium dodecyl sulfate-polyacrylamide gel electrophoresis and transferred onto polyvinylidene difluoride membranes. Membranes were blocked with 5\% non-fat milk for $2 \mathrm{~h}$, which was dissolved in $1 \%$ Tris-buffered saline with Tween 20 (TBS-T) buffer and incubated with primary antibodies against MMP-13 (sc-31811; 1:500; polyclonal goat IgG) and with monoclonal mouse IgG1 $\beta$-actin (sc-130301; 1:5,000; both Santa Cruz Biotechnology, Dallas, USA) as the internal reference. Both incubations were for $1 \mathrm{~h}$. Membranes in the buffer were gently shaken at $4^{\circ} \mathrm{C}$ overnight, and then washed with $1 \%$ TBS-T for 3 min thrice, followed by incubation with the appropriate horseradish peroxidase-labeled secondary antibodies for $1 \mathrm{~h}$ at room temperature. Proteins were visualized using enhanced chemiluminescence reagent (Beyotime Institute of Biotechnology, Haimen, China). A ChemiDoc XRS ${ }^{+}$(Bio-Rad Laboratories, Hercules, CA, USA) system was used to analyze the protein bands. Data from three independent experiments were obtained and calculated as the ratio of the gray value of MMP-13 protein divided by that of $\beta$-actin.

Statistical analysis. All data were expressed as the mean \pm standard deviation. Statistical differences were evaluated using one-way analysis of variance and $\mathrm{P}<0.05$ was considered to indicate a statistically significant difference. 
Table II. Quantitative polymerase chain reaction components.

\begin{tabular}{lcc}
\hline Content & Volume $(\mu \mathrm{l})$ & Concentration \\
\hline cDNA & 1 & - \\
Forward primer & 0.5 & $20 \mathrm{pmol} / \mu \mathrm{l}$ \\
Reverse primer & 0.5 & $20 \mathrm{pmol} / \mu \mathrm{l}$ \\
2X Mix & 12.5 & $1 \mathrm{X}$ \\
$10 \mathrm{X} \mathrm{SYBR} \mathrm{Green} \mathrm{I}$ & 1 & $0.4 \mathrm{X}$ \\
ddH $_{2} \mathrm{O}$ & 9.5 & - \\
Total volume & 25 & - \\
\end{tabular}

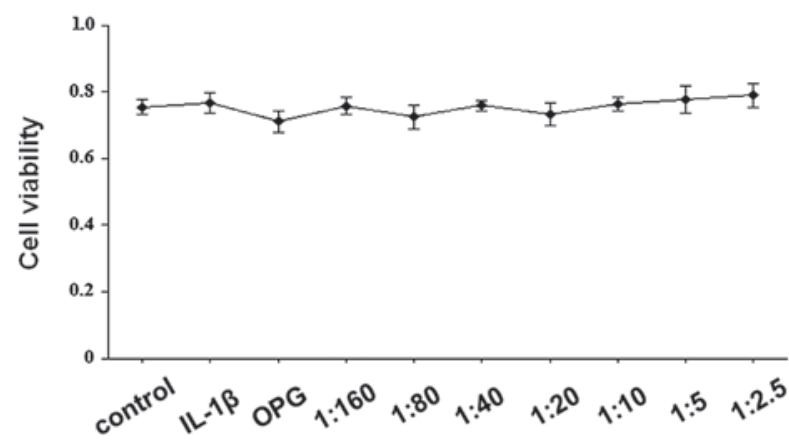

Figure 1. Effects of OPG and receptor activator of nuclear factor $\kappa \beta$ ligand/OPG on SW1353 cell viability. Cells were treated with $200 \mathrm{ng} / \mathrm{ml}$ OPG at various concentrations of receptor activator of nuclear factor $\kappa \beta$ ligand $(1.25-80 \mathrm{ng} / \mathrm{ml})$, for $24 \mathrm{~h}$. Data are expressed as the mean \pm standard deviation. OPG, osteoprotegerin, IL-1 $\beta$, interleukin-1 $\beta$.

\section{Results}

Effects of OPG and RANKL/OPG on SW1353 cell viability. The cytotoxic effect of OPG (200 ng/ml) and RANKL/OPG on SW1353 cells at various ratios (1:160, 1:80, 1:40, 1:20, 1:10, 1:5 and 1:2.5; OPG, $200 \mathrm{ng} / \mathrm{ml}$; RANKL, $1.25-80 \mathrm{ng} / \mathrm{ml}$ ) was assessed using an MTT assay. As shown in Fig. 1, cell viability values were consistently $>70 \%$, indicating that $\mathrm{OPG}$ and RANKL/OPG did not exhibit significant cytotoxic effects. The RANKL/OPG mixture at these ratios was used in the subsequent experiments.

MMP-13 mRNA expression levels in IL-1 $\beta$-stimulated SW1353 cells treated with $O P G$ and RANKL/OPG. SW1353 cells were treated with OPG $(200 \mathrm{ng} / \mathrm{ml})$ and RANKL/OPG at various ratios $(1: 160,1: 80,1: 40,1: 20,1: 10,1: 5$ and 1:2.5; OPG, $200 \mathrm{ng} / \mathrm{ml}$; RANKL, $1.25-80 \mathrm{ng} / \mathrm{ml}$ ) for $1 \mathrm{~h}$, and were subsequently stimulated by $5 \mathrm{ng} / \mathrm{ml} \mathrm{IL}-1 \beta$ for $24 \mathrm{~h}$. Total RNA and cell extracts were collected after $48 \mathrm{~h}$ and the mRNA expression levels of MMP-13 were detected in the cell extracts by RT-qPCR. As demonstrated in Fig. 2, OPG significantly inhibited the expression levels of MMP-13 mRNA ( $\mathrm{P}<0.05$ vs. IL-1 $\beta$-stimulated cells). MMP-13 mRNA expression levels were significantly elevated by the increasing RANKL/OPG ratio in a concentration-dependent manner $(\mathrm{P}<0.001$ vs. IL-1 $\beta$-stimulated cells).

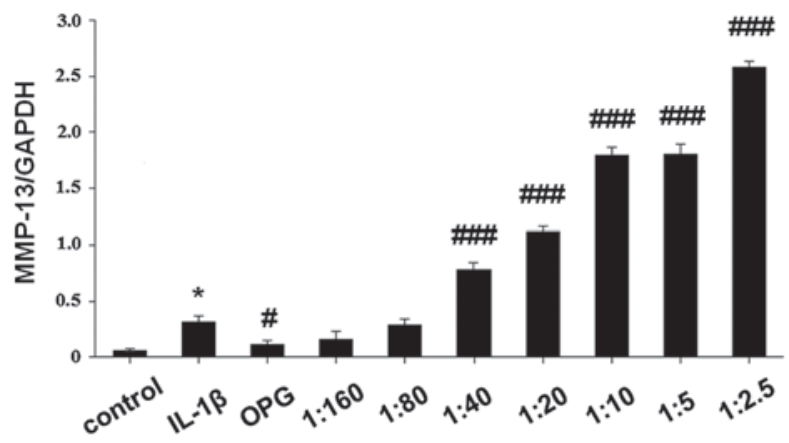

Figure 2. Relative mRNA expression levels of MMP-13 in IL-1 $\beta$-stimulated SW1353 cells, normalized to GAPDH. Data are expressed as the mean \pm standard deviation. ${ }^{*} \mathrm{P}<0.05$ vs. control; ${ }^{\#} \mathrm{P}<0.05$, ${ }^{\# \#} \mathrm{P}<0.001$ vs. IL- $1 \beta$-stimulated cells. MMP, matrix metallopeoteinase; OPG, osteoprotegerin; IL-1 $\beta$, interleukin-1 $\beta$.

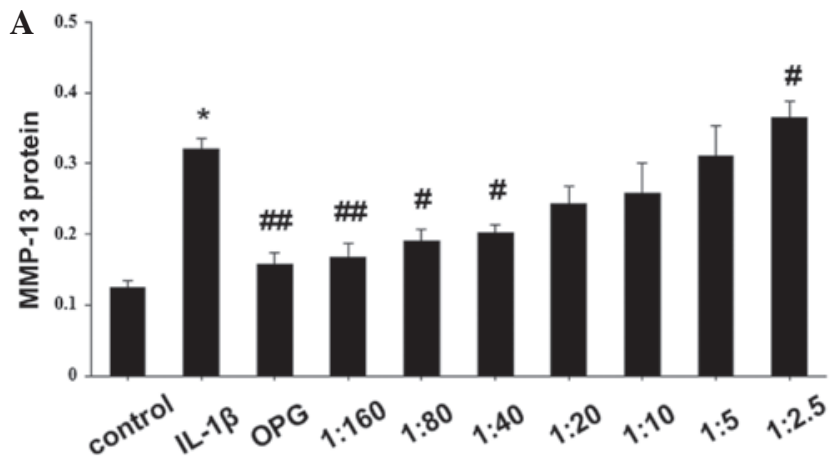

B
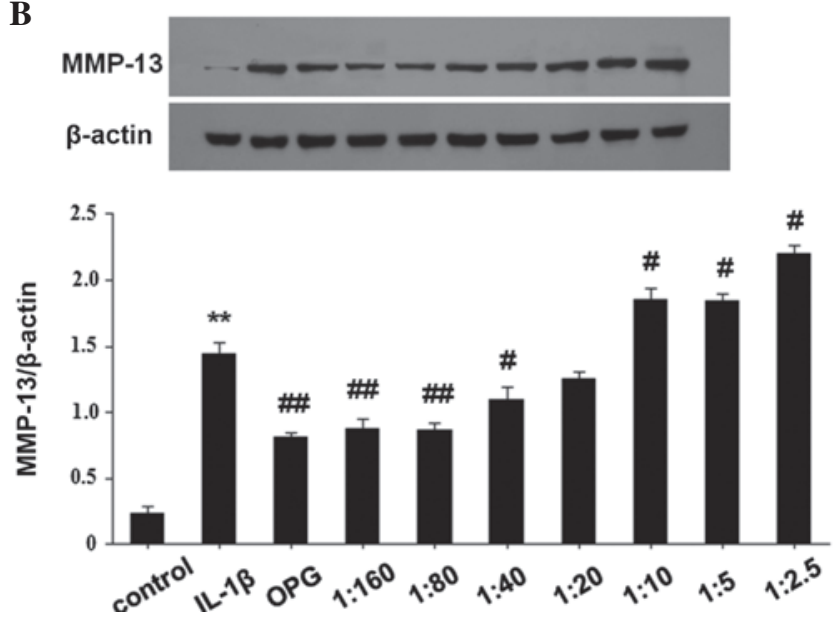

Figure 3. (A) MMP-13 protein expression in cultured supernatant by enzyme-linked immunosorbent assay. ${ }^{*} \mathrm{P}<0.05$ vs. control; ${ }^{\#} \mathrm{P}<0.05,{ }^{\# \#} \mathrm{P}<0.01$ vs. IL-1 $\beta$-stimulated cells. (B) Western blotting analysis of MMP-13 protein expression levels in IL-1 $\beta$-induced SW1353 cells, normalized to $\beta$-actin. Data are expressed as the mean \pm standard deviation. ${ }^{* *} \mathrm{P}<0.05$ vs. control; ${ }^{\#} \mathrm{P}<0.05,{ }^{\# \#} \mathrm{P}<0.01$ vs. IL-1 $\beta$-stimulated cells. ${ }^{* *} \mathrm{P}<0.05$ vs. control; ${ }^{\#} \mathrm{P}<0.05$, ${ }^{\# \#} \mathrm{P}<0.01$ vs. IL-1 $\beta$-stimulated cells. MMP, matrix metalloproteinase; OPG, osteoprotegerin; IL-1 $\beta$, interleukin-1 $\beta$.

effect of OPG and RANKL/OPG on MMP-13 protein expression levels, SW1353 cells were pretreated with OPG $(200 \mathrm{ng} / \mathrm{ml})$ and RANKL/OPG at various ratios $(1: 160,1: 80,1: 40,1: 20$, 1:10, 1:5, 1:2.5; OPG, $200 \mathrm{ng} / \mathrm{ml}$; RANKL, 1.25-80 ng/ml) for $1 \mathrm{~h}$, followed by co-incubation with IL-1 $\beta(5 \mathrm{ng} / \mathrm{ml})$ for 
24 h. MMP-13 protein was extracted and analyzed by western blot analysis, and the supernatant was collected and analyzed using an ELISA kit (Fig. 3). The results of protein expression analysis were consistent with that of RT-qPCR. As shown in Fig. 3, OPG treatment significantly reduced MMP-13 protein expression levels ( $\mathrm{P}<0.01$ vs. IL-1 $\beta$-stimulated cells); however, as the RANKL/OPG ratio increased, MMP-13 protein expression was significantly enhanced in IL-1 $\beta$-stimulated SW1353 cells ( $\mathrm{P}<0.05$ vs. IL-1 $\beta$-stimulated cells).

\section{Discussion}

Despite current treatment methods, including total joint arthroplasty, OA remains a troublesome disease that affects numerous elderly people $(24,25)$. In the present study, MMP-13 mRNA and protein expression levels were elevated in IL-1 $\beta$-stimulated SW1353 human chondrosarcoma cells treated with an increased RANKL/OPG ratio. To the best of our knowledge, the present study was the first report to investigate the association between RANKL/OPG at various ratios and MMP-13, which indicates that RANKL/OPG may have an important role in the progression of OA.

OA development is an irreversible bone disorder caused by cartilage destruction due to the degradation of type II collagen (26). Previous studies have demonstrated that aberrant expression of MMPs has a pivotal role in the destruction of articular cartilage $(14,27)$. MMPs, as a family of collagenolytic enzymes, regulate various functions in articular cartilage, including turnover, catabolism and the degradation of the extracellular matrix. Among all MMPs, MMP-13 is the primary collagenase in OA, with an activity on type II collagen that is much higher than the other MMPs (28). MMP-13 is predominantly localized in the deeper layers of cartilage (29). In a study performed by Upton et al (30), increased RANKL mRNA expression levels were observed in grade II OA cartilage, particularly in the deep layer of cartilage. Various previous studies have reported that RANKL is expressed by chondrocytes in normal and OA cartilage $(12,31)$. However, the role of RANKL in OA is yet to be fully elucidated, and the association between RANKL/OPG and MMP-13 may aid understanding of this mechanism. The findings of the present study showed that an elevated ratio of RANKL/OPG increased the expression of MMP-13. Although the exact underlying mechanism remains unclear, these results indicate that RANKL overexpression may exacerbate cartilage destruction by increasing the expression of MMP-13. A previous biochemical analysis of the circulating levels of macromolecules released from cartilage and bone in humans revealed a convergence of the pathological processes in cartilage and subchondral bone in OA at each stage (6). Furthermore, a previous study demonstrated that RANKL secreted by chondrocytes diffuse across the thin layer of calcified cartilage into subchondral bone, resulting in morphological changes to subchondral bone, which is an important factor in OA pathophysiology (30). Combined with the results of the present study, we hypothesize that RANKL overexpression in subchondral bone may diffuse into cartilage and elevate MMP-13 expression levels, which subsequently accelerates cartilage degradation.

In conclusion, to the best of our knowledge, the present study demonstrated for the first time that an increased
RAKNL/OPG ratio induces MMP-13 mRNA and protein expression. These finding may indicate a potential strategy for OA treatment.

\section{Acknowledgements}

This work was supported by the National Natural Science Foundation of China (grant no. 31171672). The authors would also would like to thank the Beijing Key Laboratory of Translation Medicine in Liver Cirrhosis (Beijing, China) and the National Clinical Research Center of Digestive Diseases (Beijing, China) for assistance.

\section{References}

1. Moyer RF, Ratneswaran A, Beier F and Birmingham TB: Osteoarthritis year in review 2014: Mechanics - basic and clinical studies in osteoarthritis. Osteoarthritis Cartilage 22: 1989-2002, 2014.

2. Hayami T, Pickarski M, Wesolowski GA, McLane J, Bone A, Destefano J, Rodan GA and Duong LT: The role of subchondral bone remodeling in osteoarthritis: Reduction of cartilage degeneration and prevention of osteophyte formation by alendronate in the rat anterior cruciate ligament transection model. Arthritis Rheum 50: 1193-1206, 2004.

3. Kaspiris A, Mikelis C, Heroult M, Khaldi L, Grivas TB Kouvaras I, Dangas S, Vasiliadis E, Lioté F, Courty J and Papadimitrou E: Expression of the growth factor pleiotrophin and its receptor protein tyrosine phosphatase beta/zeta in the serum, cartilage and subchondral bone of patients with osteoarthritis. Joint Bone Spine 80: 407-413, 2013.

4. Kwan Tat S, Pelletier JP, Lajeunesse D, Fahmi H, Lavigne M and Martel-Pelletier J: The differential expression of osteoprotegerin (OPG) and receptor activator of nuclear factor kappaB ligand (RANKL) in human osteoarthritic subchondral bone osteoblasts is an indicator of the metabolic state of these disease cells. Clin Exp Rheumatol 26: 295-304, 2008.

5. Hayami T, Pickarski M, Zhuo Y, Wesolowski GA, Rodan GA and Duong LT: Characterization of articular cartilage and subchondral bone changes in the rat anterior cruciate ligament transection and meniscectomized models of osteoarthritis. Bone 38: 234-243, 2006.

6. Petersson IF, Boegård T, Svensson B, Heinegård D and Saxne T: Changes in cartilage and bone metabolism identified by serum markers in early osteoarthritis of the knee joint. $\mathrm{Br}$ J Rheumatol 37: 46-50, 1998.

7. Martin TJ: Historically significant events in the discovery of RANK/RANKL/OPG. World J Orthop 4: 186-197, 2013.

8. Walsh MC and Choi Y: Biology of the RANKL-RANK-OPG System in Immunity, Bone, and Beyond. Front Immunol 5: 511, 2014.

9. Jones DH, Kong YY and Penninger JM: Role of RANKL and RANK in bone loss and arthritis. Ann Rheum Dis 61 (Suppl 2): ii32-ii39, 2002.

10. Shimizu S, Asou Y, Itoh S, Chung UI, Kawaguchi H, Shinomiya K and Muneta T: Prevention of cartilage destruction with intraarticular osteoclastogenesis inhibitory factor/osteoprotegerin in a murine model of osteoarthritis. Arthritis Rheum 56: 3358-3365, 2007.

11. Amizuka N, Shimomura J, Li M, Seki Y, Oda K, Henderson JE, Mizuno A, Ozawa $\mathrm{H}$ and Maeda T: Defective bone remodelling in osteoprotegerin-deficient mice. J Electron Microsc (Tokyo) 52: 503-513, 2003.

12. Komuro H, Olee T, Kühn K, Quach J, Brinson DC, Shikhman A, Valbracht J, Creighton-Achermann L and Lotz M: The osteoprotegerin/receptor activator of nuclear factor kappaB/receptor activator of nuclear factor kappaB ligand system in cartilage. Arthritis Rheum 44: 2768-2776, 2001.

13. Pritzker KP, Gay S, Jimenez SA, Ostergaard K, Pelletier JP, Revell PA, Salter D and van den Berg WB: Osteoarthritis cartilage histopathology: Grading and staging. Osteoarthritis Cartilage 14: 13-29, 2006.

14. Troeberg $L$ and Nagase $H$ : Proteases involved in cartilage matrix degradation in osteoarthritis. Biochim Biophys Acta 1824: 133-145, 2012. 
15. Takaishi H, Kimura T, Dalal S, Okada Y and D'Armiento J: Joint diseases and matrix metalloproteinases: A role for MMP-13. Curr Pharm Biotechnol 9: 47-54, 2008.

16. Burrage PS, Mix KS and Brinckerhoff CE: Matrix metalloproteinases: Role in arthritis. Front Biosci 11: 529-543, 2006.

17. Haynes DR, Barg E, Crotti TN, Holding C, Weedon H, Atkins GJ, Zannetino A, Ahern MJ, Coleman M, Roberts-Thomson PJ, et al: Osteoprotegerin expression in synovial tissue from patients with rheumatoid arthritis, spondyloarthropathies and osteoarthritis and normal controls. Rheumatology (Oxford) 42: 123-134, 2003

18. Jiang Y and Tuan RS: Origin and function of cartilage stem/progenitor cells in osteoarthritis. Nat Rev Rheumatol 11: 206-212, 2015.

19. Silverwood V, Blagojevic-Bucknall M, Jinks C, Jordan JL, Protheroe $\mathrm{J}$ and Jordan KP: Current evidence on risk factors for knee osteoarthritis in older adults: A systematic review and meta-analysis. Osteoarthritis Cartilage 23: 507-515, 2015.

20. Blagojevic M, Jinks C, Jeffery A and Jordan KP: Risk factors for onset of osteoarthritis of the knee in older adults: UA systematic review and meta-analysis. Osteoarthritis Cartilage 18: 24-33, 2010

21. Tetsunaga T, Nishida K, Furumatsu T, Naruse K, Hirohata S, Yoshida A, Saito T and Ozaki T: Regulation of mechanical stress-induced MMP-13 and ADAMTS-5 expression by RUNX-2 transcriptional factor in SW1353 chondrocyte-like cells. Osteoarthritis Cartilage 19: 222-232, 2011.

22. Gebauer M, Saas J, Sohler F, Haag J, Söder S, Pieper M, Bartnik E, Beninga J, Zimmer R and Aigner T: Comparison of the chondrosarcoma cell line SW1353 with primary human adult articular chondrocytes with regard to their gene expression profile and reactivity to IL-1beta. Osteoarthritis Cartilage 13: 697-708, 2005.
23. Livak KJ and Schmittgen TD: Analysis of relative gene expression data using real-time quantitative PCR and the $2^{-\Delta \Delta \mathrm{C}}$ method. Methods 25: 402-408, 2001.

24. Zhang HY, Blunt L, Jiang XQ, Brown L, Barrans S and Zhao Y: Femoral stem wear in cemented total hip replacement. Proc Inst Mech Eng H 222: 583-592, 2008.

25. Zhang HY, Brown L, Barrans S, Blunt L and Jiang XQ: Investigation of relative micromotion at the stem-cement interface in total hip replacement. Proc Inst Mech Eng H 223: 955-964, 2009.

26. Sulzbacher I: Osteoarthritis: Histology and pathogenesis. Wien Med Wochenschr 163: 212-219, 2013.

27. Malemud CJ: Matrix metalloproteinases (MMPs) in health and disease: An overview. Front Biosci 11: 1696-1701, 2006

28. Konttinen YT, Ainola M, Valleala H, Ma J, Ida H, Mandelin J, Kinne RW, Santavirta S, Sorsa T, López-Otín C and Takag M: Analysis of 16 different matrix metalloproteinases (MMP-1 to MMP-20) in the synovial membrane: Different profiles in trauma and rheumatoid arthritis. Ann Rheum Dis 58: 691-697, 1999.

29. Fernandes JC, Martel-Pelletier J, Lascau-Coman V, Moldovan F, Jovanovic D, Raynauld JP and Pelletier JP: Collagenase-1 and collagenase-3 synthesis in normal and early experimental osteoarthritic canine cartilage: An immunohistochemical study. J Rheumatol 25: 1585-1594, 1998

30. Upton AR, Holding CA, Dharmapatni AA and Haynes DR: The expression of RANKL and OPG in the various grades of osteoarthritic cartilage. Rheumatol Int 32: 535-540, 2012.

31. van Tuyl LH, Voskuyl AE, Boers M, Geusens P, Landewé RB, Dijkmans BA and Lems WF: Baseline RANKL:OPG ratio and markers of bone and cartilage degradation predict annual radiological progression over 11 years in rheumatoid arthritis. Ann Rheum Dis 69: 1623-1628, 2010. 